\title{
"Sou um historiador e não um fornecedor de imundícies!"1 - medicina experimental e hereditariedade no naturalismo de Émile Zola
}

\author{
Marilia Mezzomo Rodrigues ${ }^{2}$
}

Franklin Baumer caracterizou o movimento romântico como o primeiro grande protesto contra o mundo moderno e a civilização científico-racional que se configurava já no século XVII e que atingiu o seu ápice no Iluminismo do século XVIII. Entende que houve uma pluralidade de romantismos, e que, mais que um movimento artístico e literário, lançou um paradigma filosófico, político e historiográfico. Embora tenha afetado mais profundamente a Alemanha, manifestouse por toda a Europa, como reação à rigidez das ideias filosóficas e científicas do Iluminismo, ao pensamento geométrico - que sujeitava a vida à razão -, ao neoclassicismo - que teria imposto regras universais e rígidas à arte e aos artistas - e ao empirismo lockeano - que limitava o conhecimento humano ao mundo das aparências. "Entendendo que os conceitos da ciência mecanicista não eram adequados, o romantismo voltou-se cada vez para analogias biológicas, descrevendo a natureza como naturans, isto é, animada por um principio vivo em oposição a uma natura naturata, isto é, um projeto

\footnotetext{
${ }^{1}$ Emile Zola, em carta a Louis Ulbach (8 de novembro de 1871), diretor-chefe do jornal La Cloche que suspendeu a publicação de La Curée, por conta da censura do governo francês sobre o autor e seu estilo. In: JOSEPHSON, Mathew. Zola e seu tempo. São Paulo: Companhia Editora Nacional, 1958. p. 162.

${ }^{2}$ Doutora em História - Universidade Federal de Santa Catarina. Contato: marilia. mezzomo@gmail.com
} 
acabado e morto.”3 Os românticos não eram anticientíficos, mas não aceitavam a ciência mecanicista; em vez disso, influenciados pela Naturphilosophie de Schelling ${ }^{4}$, concebiam um devir, uma evolução criativa. A representação newtoniana do mundo como um relógio e seu mecanismo - com peças determinadas, bem encaixadas e permanentes -, passou a concorrer com a ideia de mundo como um organismo vivo, em evolução. O "crescimento natural" das sociedades deveria ser levado em conta, em detrimento do planejamento com base nos direitos individuais. Dessa concepção orgânica de sociedade também deriva a empatia romântica pela história: "em oposição à doutrina de progresso, Herder proclamou um relativismo histórico. Em oposição às tendências generalizantes dos 'filósofos', defendeu a individualidade das culturas e dos povos." Assim, cada sociedade se desenvolveria como uma planta, em continuidade com o seu passado específico, origem dos hábitos, realizações e lealdades do presente. $\mathrm{E}$ a nação (Estado-nação) se constituiria na forma mais elevada de organismo social.

Nesse sentido, Raymond Williams apontou que a concepção orgânica de sociedade prevê a estrutura de classes, cada uma delas cumprindo uma função; cada função se interligaria, num exercício da vida perfeita, garantindo o equilíbrio. Assim, o organismo permaneceria saudável, podendo desenvolver suas potencialidades. Ele também ressaltou o papel do filósofo britânico Edmund Burke, que

firmando a idéia do Estado como agente necessário da perfeição humana, contribuiu, nos termos dessa idéia, para que fosse condenado o agressivo individualismo do século dezenove. Também lançou a idéia do que viria a ser chamada 'sociedade orgânica', na qual a ênfase está antes da interrelação e continuidade das atividades humanas do que na

\footnotetext{
${ }^{3}$ BAUMER, Franklin L. O pensamento europeu moderno. volume II: Séculos XIX e XX. Lisboa: Edições 70. p. 34.

${ }^{4}$ Ideias para uma filosofia da natureza foi publicado em 1797.

${ }^{5}$ BAUMER, op. cit., p. 54. 
separação delas em esferas de interesse, cada qual governada por leis próprias. ${ }^{6}$

Para Burke, a sociedade orgânica era ameaçada e destruída pelas novas forças econômicas - tanto conservadores quanto socialistas adotaram esta concepção de sociedade; ambos tinham como inimigo comum o liberalismo. O apego a determinados aspectos do passado e a preservação arquitetônica e dos documentos vêm na esteira da preocupação com a sociedade orgânica em desintegração.

Como princípio do romantismo, Baumer ressalta a oposição ao Iluminismo; Williams frisa a oposição ao liberalismo. Por não apresentar direção única nem fundamentos programáticos, as ideias românticas apresentam muitas possibilidades de abordagem, mas em todas se destaca a concepção orgânica do mundo que enquadrou os mais diversos textos de seus adeptos. Juntamente com isso, a noção do devir passou da evolução dos organismos à evolução histórica, possibilitando também toda sorte de utopias, socialistas ou nacionalistas:

Na verdade, eram na sua maior parte sonhos e profecias, nunca muito concretas, de uma grande sociedade nunca antes vista. A viragem messiânica do pensamento romântico veio principalmente de França, depois de 1830, e com a 'segunda geração' na Inglaterra, onde um ânimo melancólico anterior deu lugar a expectativas apocalipticas, levantadas pelas revoluções francesa e industrial. Alguns nomes ligados a esta viragem são os simonianos e os fourieristas, Victor Hugo e Percy Bysshe Schelley, o historiador francês Jules Michelet e o patriota italiano Giuseppe Mazzini. Não é fácil caracterizar esquemas e sonhos tão diferentes como os falanstérios de Fourier, a Idade do Povo de Michelet e a Terceira Roma de Mazzini. Basta dizer que todos eles estavam cheios de paixão pela justiça e liberdade social e de compaixão pelos misérables, os oprimidos de uma nova era de exploração industrial. Todos recusavam ser constrangidos pelos limites 'clássicos',

${ }^{6}$ WILLIAMS, Raymond. Cultura e sociedade. São Paulo, Cia Editora Nacional, 1969. p. 34. 
Marília Mezzomo Rodrigues

e todos exibiam uma indiferença e desprezo no que respeita aos meios. ${ }^{7}$

Juntamente com um precioso trabalho de fontes, a concepção de história de Jules Michelet está permeada de conceitos de Herder, Hegel e também de Vico: o historiador francês foi inspirado pela teoria evolucionária da cultura, pela ideia da mudança social e do "caráter orgânico da sociedade humana e a importância de reintegrar, através da história, as diversas forças e fatores e compõem a vida humana. Queria descobrir na história um "princípio de ação". Essa mesma busca também guiou outras grandes sinteses do século 19, entre as quais estão dois livros decisivos, como afirma Aloisio Teixeira - A origem das espécies, de Charles Darwin, publicada em 1859, e o Livro I de O Capital, de Karl Marx, publicado em 1867.

Ambos representavam, cada um ao seu modo, um ataque frontal e uma verdadeira demolição dos dogmas que presidiam os estudos em ciências naturais e em ciências da sociedade. Os dogmas vigentes, tanto os de fundo religioso quanto os que se apoiavam em falsos conhecimentos científicos, implicavam em grande conformismo face à realidade, em especial a dramática realidade social da época. A insatisfação intelectual que geravam não podia ser satisfeita por propostas utópicas ou anarquistas. O avanço representado pela publicação quase simultânea das obras de Darwin e de Marx colocava no centro do debate a idéia de movimento e transformação, tanto na sociedade quanto na natureza, ainda que nem os fenômenos examinados, nem a metodologia, muito menos o próprio conceito de movimento e transformação fossem os mesmos nos dois autores. ${ }^{9}$

Essas obras trazem a marca das teorias orgânicas, cuja influência transbordara para sempre dos limites do pensamento romântico, para instaurar uma nova reflexão acerca

\footnotetext{
7 BAUMER, op. cit., p. 49.

${ }^{8}$ WILSON, Edmund. Rumo à Estação Finlândia. São Paulo: Círculo do Livro, s/d. p. 13.

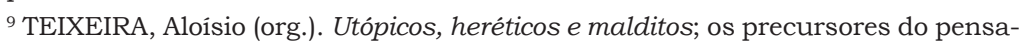
mento social de nossa época. Rio de Janeiro: Record, 2002. p. 315-6.
} 
do mundo, em quaisquer que fossem as correntes de pensamento e os campos de atuação de cientistas e intelectuais; mas já fazem parte do ideário do cientismo do século XIX. Neste, conceitos do classicismo do século XVIII não desapareceram, foram reelaborados, assim como têm, de alguma forma, as ideias românticas como ponto de partida para reflexões que buscavam o rigor de um método.

Coexistindo com as outras concepções filosóficas, políticas, econômicas e artísticas do século XIX, o ideário cientista também passou a ser uma possibilidade para lidar e explicar as mudanças naturais e sociais; todas as questões poderiam (e deveriam) ser respondidas de modo científico. Pode-se dizer que as concepções de organismo social e devir histórico, além da vontade de se produzir conhecimento objetivo, se encontraram nas principais obras da segunda metade do século 19. Se Darwin apresentou as evidências científicas da evolução, indo além das enunciações e especulações que já existiam sobre o tema, percebe-se, por exemplo, que Comte buscou sintetizar uma ciência da sociedade; Renan, a ciência da religião; Marx concebeu seu socialismo como científico; Stuart Mill concebia a ciência da natureza humana; Émile Zola, o grande nome do naturalismo literário, imaginou uma literatura unida à ciência, inspirando-se nas formulações do fisiologista Claude Bernard (1813-1878) ${ }^{10}$ que, por sua vez, entendia que a medicina deveria deixar de ser a "arte de curar" e estabelecer um corpus científico, a medicina experimental. Havia que se superar o "olhar dos nosógrafos"11

Seu livro Introdução ao estudo da medicina experimental (1865) marcou profundamente as criações literárias de Émile Zola e forneceu os princípios para a formulação de um novo método criativo na literatura. Mas antes dele, outro objeto da pesquisa científica fascinara Zola, a ponto de influenciar seus argumentos literários: a hereditariedade.

\footnotetext{
${ }^{10}$ BAUMER, op. cit, 63.

${ }^{11}$ FOUCAULT, Michel. O nascimento da clínica. 4 ed. Rio de Janeiro: Forense Universitária, 1994. p. 136.
} 
Presente em textos da Antiguidade, o interesse pela hereditariedade já constava na teoria da pangênese de Hipócrates e na Parva Naturalia de Aristóteles, entre outros. Mas foi no século 19 que se produziram as grandes sinteses sobre o tema, quando as ideias de Lamarck ganharam força para a explicação do seu funcionamento. A teoria da transmutação, conhecida como lamarckismo, formulada pelo naturalista francês Jean-Baptiste de Monet, cavalheiro de Lamarck (1744-1828), teve grande impacto na comunidade científica ocidental, sendo desenvolvida e revitalizada até o século XX. Os estudos de Lamarck concentraram-se na influência do meio ambiente no desenvolvimento dos órgãos dos seres vivos, sobre a modificação desses órgãos de acordo com sua utilização e sobre a hereditariedade dos caracteres adquiridos. ${ }^{12}$ Somente na segunda metade do século XIX é que uma teoria que se contrapunha à tradição lamarckista ganhou força, quando August Weismann reconheceu a seleção germinal como auxiliar da seleção natural. E, mais conhecido apenas no século XX, o Experimento sobre a hibridização das plantas de Gregor Mendel já havia sido publicada nos Anais da Sociedade de Naturalistas de Brünn em 1865. Muitos outros estudos foram realizados, tentando encontrar respostas que dessem conta de uma explicação para a transmissão de caracteres, mas até aproximadamente 1870 , ainda não se conhecia totalmente a função dos espermatozóides na fecundação, para citar apenas um entre vários fenômenos sobre os quais se tentava elaborar uma teoria sólida.

Foi em todas essas teorias médicas sobre a hereditariedade do século XIX que Émile Zola pôde encontrar caminhos possiveis para sua literatura. Ele leu a obra de Moreau de Tours, Da identidade do estado do sonho e da loucura (1855), o Tratado das degenerescências de Auguste Morel (1857) e a Fisiologia das Paixões de Charles Letourneau (1868). Entre os dossiês preparatórios que organizava antes de começar a escrever, há anotações sobre a Hereditariedade nas doenças

${ }^{12}$ Disponivel em <http://www.infoscience.fr/histoire/biograph/biograph. php3?Ref=40> Consultado em 08/03/2007. 
do sistema nervoso (1886), de Jules Déjerine, assim como sobre Ensaios sobre a hereditariedade e a seleção natural, de Weismann. ${ }^{13}$ Mas foi sobretudo o Tratado filosófico e fisiológico da hereditariedade natural (dois volumes, 1847 e 1850), do médico Prosper Lucas, a obra sobre o tema que mais impressionou Zola, a ponto de utilizá-la praticamente como fio condutor para sua saga familiar - os 20 livros de Os RougonMacquart: história natural e social de uma família no segundo Império, publicados entre 1871 e $1893 .{ }^{14}$

A força da obra do Dr. Lucas está manifesta em muitos registros do século XIX. No primeiro capítulo de A origem das espécies - Variação das espécies no estado doméstico-, Charles Darwin, escrevendo sobre a hereditariedade, ressaltou: "a melhor obra e mais completa que temos sobre o assunto é a Dr. Prosper Lucas." ${ }^{15}$ Ela continuou sendo ponto de referência até o final do século, a despeito de todas as descobertas feitas na área da genética e que foram de encontro a ideias do Tratado. A hereditariedade é apresentada em três casos: eleição, quando há a semelhança exclusiva com o pai ou com a mãe; mistura, na qual ocorre representação mista e simultânea do pai e da mãe; combinação, que apresenta a dissolução dos dois autores no produto. ${ }^{16}$ Zola viu nessas conformações descritas pelo Dr. Lucas uma via original para a criação literária. Também se encontra no Tratado a teoria da impregnação ${ }^{17}$, que entendia a mulher como uma espécie

\footnotetext{
${ }^{13}$ MORGAN, Owen \& PAGĖS, Alain. Guide Emile Zola. Paris: Ellipses, 2002. p. 227. Tradução livre.

${ }^{14}$ La Fortune des Rougon (1871), La Curée (1872), Le ventre de Paris (1873), La conquête de Plassans (1874), La faute de l'abbé Mouret (1875), Son excellence Eugène Rougon (1876), L'Assomoir (1877), Une page d'amour (1878), Nana (1880), Pot-bouille (1882), Au Bonheur des Dames (1883), La joie de vivre (1884), Germinal (1885), L'Oeuvre (1886), La Terre (1887), Le Rêve (1888), La Bête humaine (1890), L’Argent (1891), La Débâcle (1892) e Le Docteur Pascal (1893).

${ }^{15}$ DARWIN, Charles. A origem das espécies. Rio de Janeiro: Ediouro, 2005. p. 28.

${ }^{16}$ LUCAS, Prosper. Traité philosophique et physiologique de l'hérédité naturelle. Tome Second. Paris: Libraire de l'Académie Nationale de Médecine, 1850. p. 397434

${ }^{17}$ Para outras informações acerca da teoria da impregnação, ver CAROL, Anne. La télégonie, ou les nuances de l'hérédité féminine. In Rives nord-méditerranéen-
} 
de placa sensivel, na qual restariam "impressões", caracteres de seu primeiro parceiro sexual. Mesmo que a mulher tivesse filhos com outro homem, os caracteres do "primeiro amante" seriam transmitidos às crianças. Essa teoria coexistia com a tradição hipocrática, que postulava a necessidade das "sementes" masculina e feminina para a geração. No final do século XVII e por todo o século XVIII, estudos tentaram comprovar a predominância do gameta feminino sobre o masculino na geração e vice-versa, dividindo os estudiosos em dois campos. Muitas polêmicas acabaram cessando no século XIX, mas diferentes teorias sobre a hereditariedade, algumas obscuras, conviviam. Muitas encontraram respaldo no imaginário popular, na tradição. Outras reforçavam concepções de moral da sociedade industrial, principalmente no que se referia ao papel da mulher - mesmo que o alvo desses estudos não fosse este. Seja como for, o que se transmitia à nova geração e quem transmitia eram preocupações recorrentes, presentes nas mitologias universais sobre a vida e a morte.

Jules Michelet também era adepto da teoria da impregnação, presente em $O$ amor (1859) e da qual se encontram traços mesmo na História da França. Foi justamente nos textos de Michelet que Émile Zola dela tomou conhecimento pela primeira vez, antes da obra do Dr. Lucas. Leitor de Michelet, Zola encontrou no historiador, de acordo com suas próprias palavras, um "anatomista impiedoso, que vasculha as pessoas até as entranhas. Aqui, tratamos de homens e não de manequins solenes e grotescos; a história é explicada pelo sangue e pelos nervos, pelos apetites e covardias, pelas personalidades e fatalidades humanas." 18

Outro historiador caro a Zola foi Hippolyte Taine (18281893); crítico literário, entre suas atividades como professor e escritor, seguiu cursos no Museu e Academia de Medicina em Paris. Em sua tese de doutorado, Estudo sobre as fábu-

nes, 24-2006 - Hérédités, héritages, [En ligne], mis en ligne le : 29 décembre 2008. Disponivel em <http://rives.revues.org/document550.html> Consultado em 28/02/2009. Tradução livre.=

18 BECKER, Colette. Zola: le saut dans les étoiles. Paris: Presse de la Sorbonne Nouvelle, 2002. p. 50. Tradução livre. 
las de La Fontaine (1853), aplicou pela primeira vez as premissas de seu método crítico, que entende todo escritor por sua "faculdade mestra", própria a cada artista, determinada por três fatores: o meio, o momento e a raça. ${ }^{19}$ Em trabalhos subsequentes, estendeu esta ideia à história das nações; postulava que todos os fenômenos humanos poderiam ser entendidos nas novas perspectivas abertas pelas ciências naturais. Zola conheceu Taine quando trabalhava na livraria Hachette ${ }^{20}$, que publicava, além dos livros, boletins de resenhas e relatórios como o Boletim do livreiro e do amador (amateur) de livros. Foi para este boletim que Zola resenhou História da literatura inglesa e Novos ensaios de crítica da história, ambos de Taine, interessando-se pela possibilidade de se explicar as obras pelos fatos históricos e fisiológicos, explicar o indivíduo por sua época e seu meio. Admirava a "exatidão da ciência" do método de Taine ${ }^{21}$, mas não o aceitava completamente, por acreditar que nele a personalidade do artista não recebia a importância que merecia.

De toda a forma, em Thérèse Raquin (1867), um de seus chamados "romances da juventude"22, Zola introduziu na întegra a frase de Taine: "O vício e a virtude são produtos como o vitríolo e o açúcar", retirada da História da literatura inglesa. ${ }^{23}$ Em Thérèse Raquin, Zola também utilizou a teoria dos temperamentos. Retirada da tradição hipocrática dos quatro humores - sangue, linfa, bile amarela, bile negra - e das possiveis patologias humorais, a teoria foi aprofundada por Galeno, que fez corresponder temperamentos a cada indivíduo a partir da prevalência de determinado humor - têmse, assim, os temperamentos sanguíneo, fleumático, colérico e melancólico. Assim como as ideias acerca da hereditarieda-

\footnotetext{
${ }^{19}$ LAVIELLE, Véronique et al. Dictionnaire d'Émile Zola; as vie, son oeuvre, son époque. Paris: Éditions Robert Laffond, 1993. p. 405. Tradução livre.

${ }^{20}$ Ibidem.

${ }^{21}$ MORGAN e PAGĖS, op. cit., p. 55.

${ }^{22}$ São os cinco romances que precedem Os Rougon-Macquart: La confession de Claude (1865), Le voeu d'une morte (1866), Les mystères de Marseille (1867), Thérèse Raquin (1867), Madeleine Férat (1868).

${ }^{23}$ MORGAN e PAGĖS, op. cit., p. 55.
} 
de, aquelas acerca dos humores e temperamentos também tiveram grande aceitação, até o final do século XIX e início do posterior. Em 1789, Kant lançou mão desta teoria em Anthropology. Ela foi atualizada pelo romantismo e, na segunda metade do século XIX, teve uma obra capital a ela dedicada: Fisiologia dos escritores ou Ensaio de crítica natural, do crítico francês Émile Deschanel, publicada em 1864. O autor, republicano convicto, foi exilado durante toda a década de 1850 na Bélgica; retornando à França, elegeu-se deputado e senador vitalício. Foi nomeado professor de letras modernas no Collège de France e, graças a seu prestígio, suas conferências passaram a ser publicadas pela Hachette - onde trabalhava Zola. Interessado pelas teorias de Deschanel, que já conhecia desde sua primeira publicação, Zola aprofundou-se no estudo destas, encontrando ali uma combinação que julgou a mais precisa e completa para explicar o homem. Deschanel considerava a importância do clima, do solo e da raça no comportamento humano, mas, sobretudo, insistia no papel do temperamento individual para a definição de "fisionomias pessoais", ou seja, como cada temperamento dá cores particulares ao determinismo do meio. ${ }^{24}$ Zola aí inspirou-se para enunciar a ideia fundadora de sua nova estética - a teoria da tela (théorie de l'écran):

Vemos a criação dentro de uma obra, através de um homem, através de um temperamento, uma personalidade. A imagem que se produz sobre esta tela de nova espécie é a reprodução das coisas e das pessoas colocadas para além, e esta reprodução, que não saberá ser fiel, mudará o tanto de vezes que uma nova tela venha a se interpor entre nosso olho e a criação ... A tela clássica é, em última palavra, uma lente de aumento que desenvolve as linhas e fixa as cores de passagem ... A tela romântica é, em suma, um prisma, de refração patente, que parte todo raio luminoso e o decompõe em um espectro solar ofuscante ... A tela realista é um simples óculos de leitura, muito fino, muito claro e que tem a pretensão de ser tão perfeitamente transparente que as imagens lhe

\footnotetext{
${ }^{24}$ LAVIELLE et al., op. cit., p.121; 407; PEREIRA, Patrícia do Carmo. Diferenças individuais, temperamento e personalidade; importância da teoria. In: Estudos de Psicologia, PUC-Campinas, v. 19. n. 1, p. 91-100. janeiro/abril 2002. 
atravessam e se reproduzem em seguida em toda sua realidade ... Todas as minhas simpatias, se é necessário dizer, são pela tela realista; ela contenta minha razão e eu sinto nela imensas belezas de consistência e verdade. ${ }^{25}$

Zola tomou das ciências naturais o termo naturalismo, que era empregado no meio literário desde Balzac (17991850), para designar a sua peculiar concepção realista. O termo referia-se a princípio aos estudiosos da botânica e da zoologia, mas seu sentido foi estendido ao estudo das sociedades, ou mesmo à vontade de entender suas mudanças, principalmente no que referia ao método de estudo - com dissecações, classificações, esquematizações, estabelecimento de correlações, estudo da evolução etc. "Ora, o cientista disseca não somente para ver, mas para compreender o funcionamento dos órgãos e as grandes leis vitais". O procedimento permitiria desvelar os mecanismos da vida. ${ }^{26} \mathrm{Da}$ mesma forma, para Zola, havia que se encontrar um estilo de escrita que desse conta da nova abordagem do mundo e das informações que essa abordagem permitia buscar. Deveria ser um estilo que conseguisse captar a atividade humana no que ela apresentava de simples, natural, físico - "palpável".

Uma década antes das experimentações literárias de Zola, o escritor Gustave Flaubert (1821-1880) já buscava um novo estilo para escrever, quando começou a esboçar $M a-$ dame Bovary, em 1851. Por essa época, havia retornado de uma viagem ao Oriente Médio, Turquia, Grécia e Itália. Acumulava um sem-número de leituras e remetia-se frequentemente a experiências de infância vividas no Hôtel Dieu de Rouen, hospital no qual seu pai era o cirurgião-chefe e onde morava com a família. Estava insatisfeito com o "lirismo" de suas imagens expresso em Memórias de um louco e também nas primeiras versões de Educação sentimental, que teve alterações até a publicação definitiva, em 1869. Interessou-se por um fato aparentemente banal, do qual ele tomara conhe-

${ }^{25}$ Carta de Émile Zola a Antony Valabrègue, 18 de agosto de 1864. Apud: MORGAN e PAGĖS, op. cit., p. 204-5.

${ }^{26}$ BECKER, op. cit., p. 48. 
cimento: a morte de um médico prático - criado e educado pelo pai do escritor. Tempos antes de sua morte, o prático fora envolvido num escândalo por conta de sua segunda esposa, jovem que o traía e contraía dividas em seu nome. Uma vez descoberta e sem poder saldar suas dividas, a jovem suicidou-se, deixando uma filha pequena; o prático morreu pouco tempo depois do suicídio da esposa.

Flaubert viu na descrição dessa história a possibilidade de exercitar o novo estilo de escrita. Utilizou detalhes geográficos reais, descreveu ambientes, hábitos tradicionais, detalhes de vestuário, interiores de fazendas, hotéis, casas de interior; dedicou muitos detalhes a uma farmácia, seus medicamentos, as cirurgias que nela se faziam, os humores corporais, enfim, detalhes da vida dos seres humanos que o autor afirmava não terem recebido atenção na literatura, ou ainda, que não tinham sido descritos da forma como ele descrevia. "O estilo é mais que uma maneira de escrever, mais que um produto deliberado do escritor. Persuadido que 'não há ideia sem forma, não há forma sem ideia', Flaubert enxerga-o como a manifestação mesma do objeto, das situações, das personagens, e sem que possamos distinguir a forma do conteúdo. Quando nos mantemos 'na ideia', ela é entregue com a palavra que a nomeia." ${ }^{27}$

Madame Bovary foi publicado em 1856, depois de cinco anos de pesquisas e reescrita. Provocou comoção no país; o autor e seu editor foram a julgamento por "ultraje à moral pública, religiosa e aos bons costumes". ${ }^{28}$ Como o processo causou impacto e era discutido em jornais da capital francesa e de centros menores, pessoas passaram a afirmar na imprensa terem conhecido o casal Bovary; lembravam-se de detalhes sobre pessoas, fatos e lugares - o livro de Flaubert organizara tais detalhes numa narrativa vivida, que, por sua vez, eram apropriados pelos leitores; além de obter certa visibilidade e atenção, esses leitores se sentiam quase como per-

\footnotetext{
${ }^{27}$ NADEAU, Maurice. Préface et notes; In: FLAUBERT, Gustave. Madame Bovary. Paris: Editions Rencontre, 1965, p.13. Tradução livre.

${ }^{28}$ Jugement. Gazette des Tribunaux, 9 de fevereiro de 1857. Apud: FLAUBERT, op. cit., p. 519. 
sonagens da história, uma vez que nela constavam detalhes prosaicos da vida de qualquer habitante de uma cidade pequena francesa. Temas como o de Madame Bovary já haviam sido abordados, mas o que realmente causou impressão foi a maneira de descrevê-lo e os elementos para fazê-lo. Atentese aqui para a descrição física, não apenas dos ambientes, mas dos personagens, seus temperamentos e suas reações corporais. Leitor de obras sobre ciências naturais e sociais, Gustave Flaubert cresceu num hospital e, até seus 20 anos de idade, sua vida orbitou em torno das atividades paternas. Certamente que estes elementos tiveram um papel importante na criação de sua obra e se introduziram de forma permanente na produção literária. Quanto à imagem do escritor, Flaubert encarnava o artista que vivia de rendas outras que não de seu trabalho - para ele, sua arte era algo elevado, não deveria se misturar às necessidades de sobrevivência.

Admirador e discípulo de Flaubert, Zola foi um dos escritores que colaborou para a mudança dessa imagem do artista. Partindo da escrita realista, utilizando temas como hereditariedade, devir histórico, determinismo, darwinismo e organicismo, buscando a expressão justa, que se refinava a cada obra, produziu de forma profusa, transbordante. Livros se seguiam, assim como artigos sobre a própria literatura, peças de teatro, depois tratados teóricos; artigos sobre a política e a necessidade de se engajar pela justiça, denunciar a miséria - sempre desconfiando da política partidária e da violência. "Seus argumentos são os dos direitos humanos: a liberdade de expressão, o direito à verdade, uma justiça idêntica para todos". ${ }^{29} \mathrm{O}$ escritor se expressava em seus livros e julgava necessário se expressar também sobre seu mundo através da imprensa. E era desta atividade que tirava seu sustento, pois a entendia como profissão. "A partir de entrevistas, é possivel considerar que Zola tomou a palavra em praticamente todos os periódicos de sua época. Aproximadamente 1500 artigos na imprensa parisiense, 1800 na imprensa de cidades menores, aos quais se juntam

${ }^{29}$ MITTERRAND, Henri. La verité en marche. Paris: Gallimard, 2002. p. 63. 
entre 300 e 400 entrevistas - um volume considerável de 4000 artigos." 30

Graças à expansão da alfabetização, da edição de livros baratos e ao desenvolvimento do jornalismo, houve o aumento do público leitor, e Zola

quer dirigir a esses novos leitores, aos quais seguidamente faz alusão em suas reflexões preparatórias de suas obras. Tanto é que, à diferença da maior parte dos escritores contemporâneos, ele vive de sua pena e conhece as novas condições de produção literária, o que traz consequências sobre o conteúdo dos textos - é preciso falar a esses leitores sobre o que lhes interessa - e sobre sua forma -, é preciso fazê-lo numa linguagem que é a desses leitores, alimentar seu interesse, suscitar sua curiosidade pela utilização de toda sorte de procedimentos de maneira a educá-los - objetivo que ele atribui à literatura. ${ }^{31}$

Pierre Bourdieu sublinha a mudança que Émile Zola introduziu no campo literário do século XIX, que ainda alimentava a imagem do artista verdadeiro que não deveria sobreviver da venda de sua arte - consequentemente, o artista que vivia de seu trabalho era considerado inferior. Zola vendia, conhecia os meandros das editoras, pois trabalhara nelas, assim como em jornais. Logo, para muitos, era considerado um autor menor. Mais que isso, seus personagens portadores de "taras", defeitos físicos, suas descrições dos ambientes miseráveis - que visitava e catalogava, minuciosamente, a cada novo livro - das atividades mais baixas dos habitantes das cidades e do trabalho recebiam da imprensa e da Academia as críticas mais duras. "Zola é, sem dúvida, juntamente com Hugo, o escritor mais caricaturado do XIX." ${ }^{2}$ Uma das acusações mais recorrentes dirigidas ao escritor era a de produzir "imundícies"; assim, ele era frequentemente caricaturado ao lado de "ferramentas de traba-

\footnotetext{
${ }^{30}$ MORGAN e PAGĖS, op. cit., p. 82.

${ }^{31}$ BECKER, op. cit, p. 25.

${ }^{32}$ HAMON, Philippe. Imageries; littérature et image au XIXe siècle. Edition revue et augmentée. Paris: Librairie José Corti, 2001. p. 203. Tradução livre. 
lho" como escarradeiras, penicos, bacias e outros objetos de ablução. Numa série de posters antisemitas chamada Musée des Horreurs (Museu dos Horrores), que apareceu na abertura da Exposição Universal de 1899, Zola foi representado como "o rei dos porcos", num corpo de leitão, peniquinho em punho, a espalhar o conteúdo deste pelo mapa da França. ${ }^{33}$ Em outra, Zola surge de dentro de uma latrina; ou ainda, aparece dos esgotos, saindo pelas tampas dos bueiros. ${ }^{34}$

Além de ser criticado por seus textos literários, era atacado por participar dos grandes debates públicos, por tomar partido de pessoas, opiniões ou simplesmente por defender seus pontos de vista. E esta participação acabou por criar outro espaço de reflexão sobre o mundo e outro papel para o homem de letras. Ao explicar a invenção do intelectual, Pierre Bourdieu diz:

... é provável que Zola não houvesse escapado ao descrédito a que o expunham seus sucessos de venda e a suspeita de vulgaridade que implicavam se não houvesse conseguido (sem o ter procurado) mudar, pelo menos parcialmente, os princípios de percepção e de apreciação em vigor, especialmente ao constituir como escolha deliberada e legitima o partido da independência e da dignidade específica do homem de letras, autorizado a colocar sua autoridade específica a serviço de causas politicas. Para isso era-lhe necessário produzir uma figura nova, a do intelectual, inventando para o artista uma missão de subversão profética, inseparavelmente intelectual e política, capaz de fazer aparecer como um partido estético, ético e político, feito para encontrar defensores militantes, tudo o que seus adversários descreviam como o resultado de um gosto vulgar ou depravado. Levando a seu termo a evolução do campo literário no sentido da autonomia, ele tenta impor até em politica os próprios valores de independência que se afirmavam no campo literário. ${ }^{35}$

${ }^{33}$ Musée des Horreurs n. 4, "Lei roi de porcs". Paris, 1899.

${ }^{34}$ Ver The Alfred Dreyfus Collection: drawing on history, disponivel em <http:// terpconnect.umd.edu/ cseay/dreyfus/index.html> e Caricatures et Caricature, disponivel em <http://www.caricaturesetcaricature.com/>

${ }^{35}$ BOURDIEU, Pierre. As regras da arte. São Paulo: Cia. das Letras, 2005, p.137. 
Bourdieu também vê na adesão à ciência uma forma de se afastar da imagem de autor menor, criador de histórias grosseiras:

Tudo leva a crer, em todo o caso, que a teoria do "romance experimental" oferecia-lhe um meio privilegiado de neutralizar qualquer suspeita de vulgaridade ligada à inferioridade social dos ambientes que descrevia e daqueles que atingia com seus livros: valendo-se do modelo de médicos eminentes, ele identificava o olhar do "romancista experimental" com o olhar clínico, instituído entre o escritor e seu objeto a distância objetivadora que separa as grandes sumidades médicas de seus pacientes. Essa preocupação de preservar suas distâncias nunca é tão evidente quanto no contraste em que mantém ... entre a linguagem atribuída aos personagens populares e os discursos do narrador, sempre marcados pelos sinais da grande literatura, em seu ritmo, que é o do escrito, ou em traços típicos do estilo elevado, como o uso do passado simples e do estilo indireto. ${ }^{36}$

A publicação de $O$ romance experimental, considerado o grande manifesto do romance naturalista, começou na imprensa; cinco de seus estudos apareceram primeiramente no jornal Le Messager de l'Europe (O Mensageiro da Europa), de São Petersburgo, em 1879. Em seguida, foram publicados nos periódicos franceses Le bien publique (O bem público) e Le Voltaire artigos reunidos sob os títulos Du roman (Do romance) e De la critique (Da crítica), ambos em 1880. Neste mesmo ano, a editora Charpentier reuniu todos os textos num livro. Nele, Zola exprimiu seus conceitos fundamentais, tanto teóricos quanto políticos e morais, relativos a direitos do escritor e à relação do artista com o dinheiro; há um apelo à juventude para que combata pelos ideais de vanguarda, assim como a recusa a uma certa hipocrisia republicana. $\mathrm{E}$, claro, a explanação do que vem a ser romance experimental: "o desenvolvimento da ficção assemelha-se a uma experimentação; semelhante a uma demonstração científica, o romance progride logicamente, de uma situação inicial, definida histórica e sociologicamente, a uma situação final,

${ }^{36}$ Ibidem, p. 150. 
resultante do conflito que se desenvolveu." ${ }^{37}$ Zola apoiou-se na obra Introdução ao estudo da medicina experimental de Claude Bernard e, por conta disso, a crítica o acusou (e acusa) de produzir textos rígidos, padronizados. Era incômodo o fato de Zola ter fugido das normas do romance, tentando apagar as fronteiras entre ciência e literatura. Além disso, o último herói da saga Os Rougon-Macquart é um médico - é justamente ele, o Dr. Pascal, quem deixa a reflexão final sobre toda a obra.

No momento em que explode a ofensiva espiritualista contra o positivismo e o espírito científico; em que Brunetière, de Vogüé, Bourget, Huysmans, Barrès, Bloy condenam o racionalismo, afirmando que a ciência perdeu seu prestígio e a religião reconquistou o seu o seu, o Dr. Pascal resume e enobrece os traços de um tipo, o médico, ao qual Zola porta uma grande deferência, às vezes pela natureza de seu saber, pela importância de sua missão humana e pelas descobertas futuras da ciência médica. Pascal Rougon tem por modelo Claude Bernard, herói do método experimental, da documentação e da hipótese. É o conflito entre a ciência e a fé, ou mais exatamente, entre a serenidade e a inquietude quanto ao desconhecido que dá todo o porte ao romance. ${ }^{38}$

O método experimental do Dr. Bernard baseou-se na fisiologia, ou seja, no estudo de processos físico-químicos dos organismos. Ele postulava que a medicina deveria deixar de ser uma ciência de observação apenas e passasse a experimentar, testar hipóteses, encontrar leis a partir dos fenômenos repetíveis, em condições determinadas. Titular da cadeira de fisiologia experimental no Collège de France, rejeitou o método tradicional de ensino, que consistia na transmissão dos conhecimentos médicos acumulados no passar do tempo. Para Claude Bernard, a sala de aula deveria ser um laboratório, propiciando experimentações. E acreditava que isso servia não apenas para a medicina: "no fundo, todas as ciências possuem o mesmo raciocínio e visam os mesmos objetivos. Todos querem chegar ao conhecimento da lei dos

${ }^{37}$ MORGAN \& PAGÈS, op. cit., 362.

${ }^{38}$ MITTERRAND, La vérité..., op. cit., p. 89-90. 
fenômenos de maneira a poder prever, fazer variar ou dominar estes fenômenos." ${ }^{39}$ É possivel perceber alguns caminhos das apropriações dos princípios deterministas: das ciências naturais passaram à doutrina de Taine e depois foram adotados por Auguste Comte em seu Curso de filosofia positiva, publicado entre 1830 e 1842 . No campo da medicina, somente com Claude Bernard é que receberam uma dimensão metodológica, mas também filosófica.

Para Émile Zola, a literatura também deveria fazer parte da pesquisa científica sobre o homem e o mundo e não apenas utilizar o vocabulário científico ou descrever experiências. Os escritores também deveriam experimentar, uma vez que, acreditava, o trabalho do escritor começava onde acabava o do médico - este último não poderia se permitir testar suas hipóteses sobre o efeito do álcool na herança genética, por exemplo; já o escritor poderia.

\begin{abstract}
Nós continuamos, através de nossas experiências, a tarefa do fisiologista, que continuou a do físico e a do químico. Nós fazemos, de alguma forma, a psicologia científica, para completar a fisiologia científica... Em uma palavra, nós devemos operar sobre os caracteres, sobre as paixões, sobre os fatos humanos e sociais, como o químico e o físico operam sobre os corpos brutos, como o fisiologista opera sobre os corpos vivos. É a investigação científica e é o raciocínio experimental que combatem, uma a uma, as hipóteses dos idealistas, e que substituem os romances de pura imaginação por romances de observação e experimentação. ${ }^{40}$
\end{abstract}

Contrário à ideia da arte como produto apenas da imaginação e da inspiração do escritor, Zola falava em invenção, que partia de experiências cotidianas, possuía lógica e permitiria uma literatura sobre o mundo real, permitiria que os leitores se reconhecessem nas histórias - sem a evasão para cenários idealizados e que amorteceriam a vontade. E o produto da experimentação do escritor deveria ser entendido como importante para a transformação social.

\footnotetext{
${ }^{39}$ BERNARD, Claude. Introduction a l'étude de la médecine expérimentale. 3 ed. Paris: Librairie Ch. Delagrave, 1912. p. 31.

${ }^{40}$ ZOLA, Emile. Le roman experimental. Oeuvres complètes d'Emile Zola, Tomo X. Lausanne: Imprimeries Réunies, 1968, p.1183. Grifos do autor. Tradução livre. 
Buscamos as causas do mal social; fazemos a anatomia das classes e dos indivíduos para explicar os maus funcionamentos que se produzem na sociedade e no homem. Isso seguidamente nos obriga a trabalhar com temas deteriorados, a descer até o meio das misérias e das loucuras humanas. Mas portamos os documentos necessários para que possamos, conhecendo-os, dominar o bem e o mal. Aí está o que vimos, observamos e explicamos com toda a sinceridade; agora, cabe aos legisladores fazer nascer o bem e desenvolvê-lo, a lutar contra o mal, para extirpá-lo e destrui-lo. Nenhuma necessidade será, então, mais moralizadora que a nossa, já que é sobre ela que a lei deve se basear. Estamos bem longe das tiradas em favor da virtude que não engajam ninguém! ${ }^{41}$

A opção pela ciência e pela medicina não se encontra apenas nas obras de Émile Zola, mas envolve os intelectuais de forma geral a partir da segunda metade do século 19 . A partir de 1862, por exemplo, eram organizados em Paris os "jantares Magny", duas vezes por mês. Neles, reuniam-se médicos, homens de letras e estudiosos em geral em discussões sobre a produção científica e literária de então. O tema perpassava o pensamento do período em todos os campos, provocando mudanças na forma de compreender o mundo e nele intervir. Numa observação mais ampla, é possível perceber como adquiriu contornos bem precisos, distinguindo-se, pouco a pouco, do panorama científico do início do século XIX e do período das Luzes, sem deixar de lado apropriações, definições de novos campos e reelaborações teóricas. De acordo com Raymond Williams, "o que estamos definindo é uma qualidade particular de experiência social e das relações sociais, historicamente diferente de outras qualidades particulares, o que dá o senso de uma geração ou período." ${ }^{42}$

Para Zola, a literatura que mergulhava na ciência deveria produzir personagens que apresentassem temperamentos, caracteres físicos e mentais herdados e lutassem cotidianamente para sobreviver, da melhor forma possivel, em determinados ambientes, com condições específicas de vida e trabalho. Como nenhum desses personagens deveria ser

${ }^{41}$ Ibidem, p. 1228-9.

${ }^{42}$ WILLIAMS, Raymond. Marxismo e literatura. Rio de Janeiro: Zahar Editores, 1979. p. 131. 
somente a representação de um ideal, grande parte deles se comporta como as pessoas que Zola cruzava diariamente: em ambientes miseráveis, deixavam vir à tona a "besta humana", buscavam alívio no álcool, regulavam o convívio pela violência. Para sobreviver, era necessário roubar, se prostituir. Crianças não eram pequenos anjos neste meio e frequentemente sucumbiam à violência e à fome. A doença é um elemento constante nas narrativas, tanto aquela advinda das péssimas condições do meio, quanto a doença nervosa. Ambas atacam todas as classes sociais, reproduzindo essa condição original nas gerações subsequentes. Há, sem dúvi$\mathrm{da}$, os personagens que promovem reviravoltas nas narrativas, mas mesmo essas seguem uma lógica. Assim, a bondade extrema não é recompensada apenas pelo fato de existir, por exemplo, uma vez que no mundo real as coisas não se passam dessa forma.

$\mathrm{Na}$ busca pelo "personagem real", da representação perfeita, Zola fazia pesquisa de campo para tomar notas e registrar suas impressões - todas essas notas compunham um dossiê inicial, com informações sobre o ambiente no qual a história se desenvolveria, as características das pessoas deste ambiente, vocabulário específico, atividades profissionais, detalhes históricos. Zola tinha obsessão pela documentação e pela verossimilhança. Para escrever Germinal (1885), visitou a região carbonífera francesa do Nord-Pas de Calais, na fronteira com a Bélgica. Ali, no "país negro", conviveu por muitas semanas com os mineiros, visitou suas casas, os comerciantes das cidades próximas, acompanhou a vida nessas cidades. Sobretudo, colheu depoimentos sobre a grande greve de 1884, encerrada pela violência do exército com muitas mortes. Apesar de ser claustrofóbico, desceu às galerias várias vezes, tomando notas sobre as condições de trabalho, a presença de crianças e mulheres, os mineiros que passavam dias embaixo da terra sem poder subir, a impressionante descida dos cavalos ao subterrâneo, os acidentes, assim como registrou dados sobre a geologia, a arquitetura das minas, o clima da região, as doenças respiratórias, o alcoolismo, a alta taxa de natalidade. Ali estava sua "situação 
inicial", com as definições históricas e sociológicas, depois povoada com criaturas plausiveis - afinal, um naturalista sabe que determinadas espécies não se desenvolvem em certos ambientes, que tentar colocá-los em meios adversos a sua natureza pode levar à morte. Ao contrário, Zola queria erguer personagens marcantes, que se inserissem na posteridade por conta da humanidade que carregassem; não seriam ideais, mas exemplares de determinadas condições. Por fim, deveria chegar aos seus leitores, mesmo que precisasse publicar suas obras em capítulos, nos jornais. Para ele, não havia rebaixamento da arte do autor, ao contrário. De acordo com Henri Mitterrand:

Entre as linhas de Germinal, podem-se distinguir os traços de múltiplas leituras técnicas, médicas, históricas politicas. Zola é um dos raros escritores franceses da época a tomar conhecimento, indiretamente, das teses de Marx, até então reservadas aos círculos da II Internacional. Por todo lugar, os jornais socialistas reproduzem o romance em folhetim, gratuitamente, com a autorização de Zola: "Peguem-no, ele vos pertence!". ${ }^{43}$

O talento do escritor deveria garantir que todos os elementos de seus textos fluíssem em narrativas massivas. Em carta a um amigo, Zola falou da necessidade de "construção sólida de massas, de capítulos, sucedendo-se como blocos superpostos, mordendo-se uns aos outros; pelo sopro da paixão animando o todo, correndo de uma ponta a outra da obra. Cuidar do estilo (...) mas sempre com calor e paixão. Uma torrente barulhenta, larga, e uma marcha majestosa." ${ }^{44}$

$\mathrm{Na}$ história da família Rougon-Macquart, conceitos científicos do século 19, assim como as mitologias sobre o sangue e a geração, estão mescladas à vida dos personagens. O exemplo mais marcante é $O D r$. Pascal, último livro da saga, citado anteriormente. Nele, o Dr. Pascal Rougon, médico em uma cidade pequena, trata seus pacientes pobres sem

${ }^{43}$ MITTERRAND, op. cit., p. 73

${ }^{44}$ Carta de Émile Zola a Antony Valabrègue, 18 de agosto de 1864. Apud: MORGAN \& PAGĖS, op. cit., p. 204-5. 
cobrar as consultas; o que recebe daqueles que podem pagálo, investe em suas pesquisas acerca da hereditariedade. Utiliza como objeto de estudo a própria família, a contragosto de sua mãe, da empregada e da sobrinha - a primeira teme que o filho traga à luz constrangedoras histórias de parentes com taras congênitas ou crianças ilegitimas; a empregada é apegada a toda sorte de misticismos e acredita que a ciência traz desgraças, por querer explicar fenômenos naturais que, para ela, pertenceriam a uma dimensão mágica; a sobrinha, Clotilde, é religiosa. Mas renuncia à sua fé quando entende o objetivo do tio, que é "tudo dizer, para tudo conhecer e tudo curar" ${ }^{\prime 4}$, e passa a ser sua assistente. Os dois se tornam amantes, mas são obrigados a se separar. Ela retorna a Paris e o Dr. Pascal morre, sem conhecer o filho ao qual Clotilde dera à luz. Depois do nascimento da criança, Clotilde retorna à casa do médico, onde ainda vivem a mãe e a empregada que conseguiram destruir o trabalho do médico sobre a hereditariedade. Somente a árvore genealógica da família restou. A árvore do Rougon-Macquart teve cinco conformações, de acordo com os livros e personagens que Zola ia produzindo; foi publicada e reproduzida em jornais, na introdução dos livros e mesmo no Dicionário universal e ilustrado da França contemporânea. Os detratores do autor com ela se deliciaram, comparando-a a um mapa rodoviário, por exemplo. Alphonse Daudet teria dito que se fosse ele a ter desenhado tal árvore, subiria até galho mais alto e ali se enforcaria. ${ }^{46}$

Ao colocar seu personagem montando a árvore genealógica, Zola retomou os principais personagens dos vinte livros anteriores. Na saga familiar, percebe-se que todos os livros contêm ideias iniciais que se espalham pelos vários volumes, muitas vezes mais refinadas, acrescidas de outros elementos. É como se as teorias da hereditariedade do Dr. Prosper Lucas se concretizassem nos livros, certamente atingindo mais leitores que aqueles da tese médica. A heredita-

\footnotetext{
${ }^{45}$ ZOLA, Émile. Le docteur Pascal. Les Rougon-Macquart; histoire naturelle et sociale d'une famille sous le Second Empire. Oeuvres complètes d'Emile Zola, Tome VI. Lausanne: Imprimeries Réunies, 1968. p. 1085.

${ }^{46}$ LAVIELLE et al., op. cit., p.33.

50 Revista de História Regional 14(2): 29-52, Inverno, 2009
} 
riedade passou a ser tema literário, nem sempre estruturado da mesma forma que o fez Zola, mas mesmo assim presente, reelaborado de acordo com diferentes contextos. Teve ênfase no início do século XX, principalmente após a $1^{\text {a }}$ Guerra Mundial, periodo em que o sentido dos futuros nacionais inquietava políticos, mas também intelectuais, cientistas e artistas. De certa forma, a imagem da hereditariedade passou a condensar as preocupações com o futuro.

A busca pelo aspecto científico não pode ser entendida somente como um gesto reducionista de intelectuais, naturalistas ou médicos. Como se viu, diferentes noções conviviam, eram combinadas, suas premissas reelaboradas, dando origem a novos e diversos registros. A aspiração a um estatuto científico deve também ser entendida como uma forma de se conceber o mundo e a ação sobre este. Engendrou teorias que visavam a transformação e não a conformação do mundo, assim como também possibilitou processos criativos, um diálogo com a produção artística e mesmo a redefinição do papel do artista no mundo.

\section{"Sou um historiador e não um fornecedor de imundicies!" - medicina experimental e heredita- riedade no naturalismo de Émile Zola}

Marilia Mezzomo Rodrigues

Resumo: Na segunda metade do século XIX, o romance naturalista, mais precisamente o de Émile Zola, fixava analogias entre a fisiologia e o meio, personagens determinadas por este e portadores de caracteres fisicos para além da simples aparência - doenças, defeitos, hereditariedade, saúde, tudo concorria para tornar a narrativa verossimil. Assim como os personagens, o próprio meio e as comunidades criadas pelo texto literário também parecem pulsar, tornar-se doentes ou sadios, fenecer, morrer. E tal percepção orgânica do mundo, que consequentemente modificou a forma de registrá-lo, é 
mais remota, está ligada ao movimento romântico do início daquele século, com origens no final do século XVIII.

Palavras-chave: naturalismo; organismo social; medicina experimental; romantismo; hereditariedade.

Abstract: During the second half of the $19^{\text {th }}$ Century, the naturalistic romance, more specifically that of Émile Zola, established analogies between physiology and environment, the characters it defined and those carrying physical traits beyond the simple appearances - ilnesses, defects, hereditary traits, health... everything helped to make the narrative plausible. As the characters, the environment itself and the communities created by the literary text also seem to pulse, to became ill or healthy, to whither and die. Such organic perception ot the world, which consequently changed the way it was registered, is more remote, connected to the Romantic movement of the beginning of that Century, with routes at the end of the $18^{\text {th }}$ Century.

Keywords: naturalism; social organism; experimental medicine; romanticism; hereditarity.

Artigo recebido para publicação em 30/10/2009

Artigo aprovado para publicação em 18/12/2009 